\title{
Perfil energético de cabras leiteiras hígidas acompanhadas durante o período de transição
}

Gliére Silmara Leite Soares ${ }^{[]^{*}}$, Rodolfo José Cavalcanti Souto ${ }^{[b]}$, Alexandre Tadeu Mota Macedo ${ }^{[b]}$, Jobson Filipe de Paula Cajueiro ${ }^{[a]}$, Rafael Otaviano do Rêgo ${ }^{[b]}$, Pierre Castro Soares ${ }^{[[]}$, José Augusto Bastos Afonso ${ }^{[d]}$, Carla Lopes de Mendonçą ${ }^{[d]}$

\footnotetext{
[a] Programa de Pós-Gradução em Sanidade e Reprodução de Ruminantes, Universidade Federal Rural de Pernambuco (UFRPE), Garanhuns, PE, Brasil

[b] Programa de Pós-Graduação em Ciência Veterinária, Universidade Federal Rural de Pernambuco(UFRPE), Garanhuns, PE, Brasil

[c] Departamento de Medicina Veterinária, Universidade Federal Rural de Pernambuco (UFRPE), Garanhuns, PE, Brasil

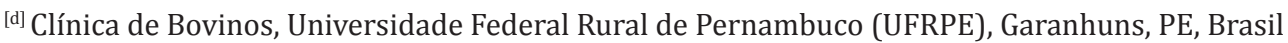

*Autor correspondente

e-mail: glieresilmara@hotmail.com

\section{Resumo}

O período de transição é considerado crítico para a cabra leiteira, uma vez que nele ocorrem importantes mudanças fisiológicas e metabólicas necessárias à adaptação decorrente da demanda energética exigida no final da gestação e início da lactação. Este trabalho teve por objetivo estabelecer o perfil energético sanguíneo de cabras leiteiras saudáveis acompanhadas durante o período de transição. Para tal, utilizou-se 94 cabras mestiças, multíparas, hígidas e prenhas, criadas no semiárido pernambucano. As propriedades adotavam o sistema de criação intensivo, onde os animais eram vacinados e vermifugados sistematicamente, e a alimentação era composta por bagaço de cana-de-açúcar, palma e farelo de trigo, milho, algodão e soja, além de sal mineral e água ad libitum. As amostras de sangue foram colhidas em sete momentos de observação: aos 30 dias antes do parto (30 dap), 20 dap, 10 dap, dia do parto, 10 dias após o parto (10dpp), 20 dpp e 30 dpp. Foram avaliadas as concentrações sanguíneas de $\beta$-hidroxibutirato (BHB), ácidos graxos não esterificados (AGNEs), glicose, frutosamina e amilase. Para a análise estatística empregou-se a análise de variância ao nível de 5\% de probabilidade avaliando-se o efeito de momento. Dentre as variáveis que compõem o perfil energético, verificou-se haver alterações fisiológicas adaptativas mais expressivas a partir dos 10 dias que precedeu o parto, verificando concentrações sanguíneas médias mais elevadas $(P<0,05)$ de AGNEs $(0,47 \mathrm{mmol} / \mathrm{L})$ e glicose $(5,31 \mathrm{mmol} / \mathrm{L})$ no momento do parto, assim como na fase inicial da lactação valores superiores $(\mathrm{P}<0,05)$ de $\mathrm{BHB}(0,45 \mathrm{mmol} / \mathrm{L})$, frutosamina $(237,11 \mu \mathrm{mol} / \mathrm{L})$ e maior atividade 
sérica da amilase (146,4U/L). A maior demanda energética gerada no final da gestação, em função do desenvolvimento fetal, eleva a taxa de lipólise liberando maior quantidade de AGNEs na corrente sanguínea. No momento do parto, as altas concentrações de hormônios glicocorticoides estimulam o aumento da gliconeogênese hepática e, consequentemente, da concentração de glicose na corrente sanguínea. Maiores concentrações de BHB no início da lactação estão relacionados a maior demanda energética da glândula mamária em função da síntese do leite. A elevação da frutosamina está relacionada ao aumento da glicemia no parto. Os valores quantitativos da concentração sanguínea destes metabólitos antes, durante e após o parto verificados neste estudo, numa condição fisiológica, será de grande valia como ferramenta laboratorial no auxílio da detecção precoce de alterações sanguíneas resultantes de distúrbios metabólicos ocorridos comumente neste período. 